\section{Original} Article

\begin{tabular}{|l|}
\hline Access this article online \\
\hline $\begin{array}{l}\text { Website: } \\
\text { www.ajobe.org }\end{array}$ \\
\hline DOI: \\
10.4103/1817-7417.86028 \\
\hline Quick Response Code: \\
\hline
\end{tabular}

Address for Correspondence: Prof. Tina Uys, Department of Sociology, University of Johannesburg, PO Box 524, Auckland Park 2006 South Africa

E-mail: tuys@uj.ac.za

\title{
Challenges in the sociology of business ethics: Researching whistleblowing
}

Tina Uys

Department of Sociology, University of Johannesburg, PO Box 524, Auckland Park 2006, South Africa

ABSTRACT

The main research focus of the sociology of business ethics is on (i) the moral foundations of people's behaviour, both within and outside the business context, (ii) how compatible or contradictory these behaviours are and (iii) how stable a society or component of a society would be if self-interest is the main governing principle, without being constrained by moral discipline. This entails providing accurate descriptions and explanations of ethical situations. Whistle-blowing research is used to examine the methodological challenges of business ethics researchers. The analysis demonstrates the importance of an integrated multi-strategy approach that would facilitate an investigation of the motivations and decision processes of individual actors in the larger social context, especially within the organisation.

Keywords: Ambiguity, Business ethics research, Descriptive ethics, Embeddedness, Methodological challenges, Motives, Sensitivity, Whistle-blowing

\section{INTRODUCTION}

Research on whistle-blowing has received increased attention in recent years. The focus has been on inter alia the nature and dynamics of the phenomenon as well as on the analysis of particular cases of whistleblowing. The academic literature generally deals with whistle-blowing as an expression of morality in organisations or as an affirmation of professional responsibility. It is sometimes seen as the result of a strong commitment to religious or humanistic values, or simply as a situation where the whistle-blower has miscalculated the costs (Rothschild and Miethe, 1994, pp. 255-256). While research on this phenomenon is being approached from the vantage point of a number of disciplines, for example business ethics, philosophy, psychology, management, law and sociology, the ethical paradox of whistle-blowing always seems to be central to the research, either explicitly or implicitly (Vandekerckhove, 2006). Miceli et al (2008: pp. 26-32) provide a useful overview of the limitations that researchers of whistle-blowing need to consider when deciding on a research design. However, these considerations do not seem to address the particular challenges faced by whistle-blowing researchers in the business ethics field. This paper attempts to address these challenges.

\section{CHALLENGES IN BUSINESS ETHICS RESEARCH}

Michael Hoffman and Jennifer Moore (1982, p. 299) define business ethics as:

"disciplined normative reflection on the nature, meaning and context of business activity. As such it deals with comprehensive questions about the justice of the economic context in which business operates and about the nature, function, structure and scope of business in that context, as well as with more specific issues raised by the relationship of business to government, the consumer, its employees, and society at large".

This definition emphasises the "primarily philosophical and normative" nature of business ethics without acknowledging that it is also "informed by social science research". George Frederickson (1993, p. 7) argues, on the other hand, that the ethical arguments of business ethics should be subjected to attempts to test them against empirical evidence. In this regard, Deon Rossouw (2002, pp. 32-34) distinguishes between three kinds of ethics, namely metaethics, prescriptive or normative ethics and descriptive ethics. Metaethics can be defined as a "philosophical reflection on the nature of moral judgments" (Starck, 2001, 
p.136). It also considers issues related to the definition of concepts.

Prescriptive ethics "entails making prescriptions or judgements about ethical issues" (Rossouw, 2002, p. 33). It therefore adopts a particular position with regard to moral choices and provides a theoretical justification for this choice. Starck (2001, p. 136) calls it applied ethics or "the attempt to choose from among various ethical approaches in deciding practical matters". The latter clearly requires an investigation into the criteria used when deciding whether behaviour is moral or not, as well as the empirical inspection of the implementation of these criteria in different contexts.

The descriptive approach focuses on providing accurate descriptions and explanations of ethical situations. Apart from people's behaviour and the characteristics of ethical situations, this approach would also investigate "what moral values people really do espouse and enact, in business and elsewhere" (Hendry, 2001, p.217).

Descriptive ethics provides the meeting place for sociology and business ethics. In this regard, Hendry (2001, p. 214) pinpoints the central research agenda of the sociology of business ethics as establishing (i) the moral foundations of people's behaviour, both within and outside the business context, (ii) the compatibility and contradictions between these behaviours and (iii) the stability of a society or constituent of a society "governed solely by the precepts of self-interest, without the constraining effects of moral discipline" (Hendry, 2001, p. 214). In particular, the central theme of such an agenda would centre on the compatibility of traditional moral values, with the increasing legitimisation of self-interest in the business world.

As a relatively new field of study, business ethics research faces certain challenges that more established academic fields have already surmounted fairly successfully (Rossouw, 2001, p. 205). Rossouw (2001, p.197) identifies three sets of such challenges related to ontological, methodological and theoretical issues.

Methodological challenges refer to the criteria that should be considered when justifying the choice of research strategies and methodologies. A main concern in this regard is the choice between a qualitative or quantitative methodology, or a combination of the two. According to Rossouw (2001, pp. 204-208), four considerations should play a role in this decision: stage of development, ambiguity, embeddedness and sensitivity. A relatively young field of study, such as business ethics, is often characterised by an immature theoretical basis and inconsistency in the way key concepts are understood. This results in the first source of ambiguity, namely the lack of agreement with regard to the definition of concepts. A second source of ambiguity is related to the non- factual nature of business ethics, which necessarily always involves the making of value-judgements. Embeddedness entails the capacity of particular methodologies to uncover the choices of individual actors with regard to ethical behaviour as well as assessing the impact of the economic setting on ethical behaviour. Sensitivity embodies the extent to which enquiries in this field are experienced by respondents as a reflection of their value as humans and, as such, addresses the essence of their being.

This paper focuses on the challenges that confront the sociology of business ethics by exploring the implications of these four methodological challenges to research practice in the field. These challenges are scrutinized by using research on the phenomenon of whistle-blowing as an example.

\section{CHOICE OF RESEARCH METHODOLOGY: THE STAGE OF DEVELOPMENT OF BUSINESS ETHICS}

The field of business ethics is relatively young. As such, it lacks the solid theoretical foundation that older fields claim to have as well as a general agreement on the meaning of key concepts. This requires that researchers in the field of business ethics should place the generation and expansion of theories in the foreground of their activities. In the process, the purpose of theory construction as it relates to the ongoing debate between normative or prescriptive versus empirical or descriptive approaches (Trevino and Weaver, 1994: p. 120) should be resolved as it impacts on decisions on the requirements of appropriate research designs and methods (Rossouw, 2001: p. 205-206).

This is particularly important with regard to research in the field of the sociology of business ethics. Gabriel Abend (2008: 87) puts the case very bluntly when he argues

"that sociology's empirical research on morality relies, implicitly or explicitly, on unsophisticated and even obsolete ethical theories, and thus is based on inadequate conceptions of the ontology, epistemology, and semantics of morality. ... Finally, I contend that in order for sociology to improve its understanding of morality, better conceptual, epistemological, and methodological foundations are needed".

Some whistle-blowing researchers, for example Park and Blenkinsopp (2009, p. 545), similarly lament the absence of a general theory explaining whistle-blowing behaviour.

\section{CHOICE OF RESEARCH METHOD: THE IMPACT OF AMBIGUITY}

Two sources of ambiguity in the field of business ethics should be considered here. In the first place, the lack of agreement with regard to the definition of concepts and, secondly, the underlying value-judgements, always inform any research activity in business ethics. 


\section{Definition of concepts}

As a relatively young field of study, business ethics is characterised by a lack of consensus about the meaning of key terms. Any researcher should therefore consider issues with regard to conceptualisation, with the emphasis on developing clear and unambiguous definitions of the major concepts in the research, from the existing theory (Brand, 2008, p. 432; Clegg et al, 2007, pp. 113-114; Rossouw, 2004, p. 30). The complexity of this activity is illustrated through considering the conceptualisation of whistle-blowing ${ }^{1}$.

A major problem with the concept of whistle-blowing is that it has been sensationalised by the media and, consequently, is used in various popularised forms with different connotations depending on the attitudes and experiences of the user. Academic authors also define whistle-blowing in various ways. Research on whistle-blowing therefore requires that the meanings attached to the term should be clarified at the beginning of the research. It could also constitute a research project on its own.

One element of the definition on which there seems to be general agreement is that whistle-blowing (or ethical resistance as it is often referred to) is the disclosure of organisational wrongdoing to those who are perceived to be in a position to take action (Glazer and Glazer 1989: 4; Jubb 1999: 83; Miceli and Near 1992: 15; Miethe 1999: 17-18; Wilmot 2000: 1051). Organisational wrongdoing could entail a wide variety of behaviours, such as criminal activity, the abuse of public funds, a miscarriage of justice, abuse of power, maladministration and danger to the health or safety of any individual (Kloppers 1997: pp. 240-241; Vinten, 1994: p.5). Organisational wrongdoing therefore consists of any illegal and/or immoral behaviour within the workplace.

A second point of agreement seems to be that an employee or former employee of the organisation should be making the disclosure of organisational wrongdoing (Calland and Dehn 2004: 3; Glazer and Glazer 1989: 4; Miethe 1999: 13; Singer et al 1998: 528; Wilmot 2000: 1051). Several authors (Johnson 2003: 4; Miceli and Near 1992: 16-17) broaden this requirement to a member or former member of an organisation, while Jubb (1999: 83) refers to "a person who has or had privileged access to data or information of an organisation". A reporter or politician who reveals examples of illegal, immoral or illegitimate acts happening outside of their particular work sphere is therefore not considered to be a whistle-blower. The fact that the whistle-blower is an insider is an essential element of the perception of betrayal. Only an insider can betray, or to put it differently, can violate loyalty and trust (Ben-Yehuda 2001: 37).

Some authors define whistle-blowing very broadly to include any disclosure of organisational wrongdoing (Alford 2001:
18; Johnson 2003: 4; Miceli and Near 1992: 16), whether sanctioned by the organisation or not, while others believe that it should be restricted to the unauthorized disclosure of information (Davis 2004: 298; Hunt 1998: 525; Glazer and Glazer 1989: 4; Vinten 1994: 5). The latter authors limit whistle-blowing to bureaucratically unauthorised forms of disclosure. It is largely this unauthorised nature of the whistle-blower's disclosure that exposes him or her to the accusation of treachery.

Geoffrey Hunt (1998: 530) identifies three main criteria in terms of which a disclosure of information could be considered to be bureaucratically unauthorised. Firstly, the disclosure could be unauthorised due to the sensitive nature of the information, in particular where secrecy clauses or issues of confidentiality are involved. Secondly, the organisation might not consider the particular employee to be sufficiently senior to make such a disclosure. Thirdly, the disclosure could be viewed as unauthorised if the employee did not follow the organisation's directives with regard to the authorised recipient of a disclosure of this nature.

A further complication in respect of the definition of whistle-blowing occurs when some authors (e.g., Miceli and Near 1992: 21-25) also include as whistle-blowers those whose work roles prescribe that they should disclose information about wrongdoing. To distinguish between what is considered normal requirements in such a function and what may be regarded as whistle-blowing, Miethe (1999: 17) argues that, in such cases, the definition of whistle-blowing should be restricted to those who go outside the prescribed channels to disclose the information, as those whistle-blowers who remain internal would not suffer victimisation. However, research has demonstrated that role-prescribed whistle-blowers are often victimised in similar ways to that of the non-role-prescribed whistleblowers (Uys, 2008).

Finally, a distinction is generally made between internal and external whistle-blowing. Whistle-blowing could occur internally when the whistle-blower bypasses the prescribed internal channels of communication or externally when the whistle-blower resorts to an external agency, which could include the media. Some authors exclude internal disclosures from the definition of whistle-blowing (Hunt 1998: 530; Johnson 2003: 4; Jubb 1999: 90-91; Petersen and Farrel 1986: 4-5), while others consider both internal and external disclosures to be whistle-blowing (Bok 1980: 278-280; Miceli and Near 1992: 25-27; Somers and Casal 1994: 272; Westin 1981: 1). Whistle-blowers are generally expected to exhaust the internal route before turning to ways of exposing the wrongdoing externally.

Most definitions also emphasise the requirement that the disclosure of the information should be in the public 
interest. While it is clearly in the public interest to expose some forms of wrongdoing, such as the dumping of toxic waste or corruption in the civil service, other issues might be more open to interpretation. This is a particular problem if the employer does not perceive the disclosure to be in the public interest or considers it to be a matter of confidentiality or security (Hunt, 1998, p. 527).

Another definitional issue is related to whether a person should only be recognised as a whistle-blower if the employer retaliates against him/her. In theory, any unauthorised disclosure of organisational wrongdoing should qualify as whistle-blowing. In practice, however, the whistle-blower only becomes defined as such once the employer responds negatively to the disclosure. This phenomenon results in a tendency to exaggerate the extent to which employers retaliate against whistle-blowers. Those whistle-blowers who do not receive any negative attention from the organisation are generally seen as conscientious employees doing their duty in protecting the interests of the organisation. "[B]y definition, most whistleblowers are retaliated against, and most of them severely" (Alford, 2001, p. 18).

The conceptualisation of central concepts is a prerequisite for conducting quality research. It is also essential in identifying possible respondents and deciding on a sampling design. These decisions impact directly on considerations of the feasibility of studying a particular explanatory research question in circumstances where it would be difficult, if not impossible, to draw a probability sample. It is, for example, a challenge to the ingenuity of a researcher wishing to establish conclusively whether women are more likely to blow the whistle than men.

Furthermore, the ethical ambiguity inherent in the lack of consistency in the understanding of concepts among research subjects should be acknowledged explicitly in the research design, and plays an important role in the choice of research strategies and methods. As Rossouw (2001, p.207) puts it:

"What is needed to accommodate these concerns about ambiguity in business ethics research are methodologies that will allow respondents the opportunity to co-construct the meaning of such ambiguous terms... Open-ended questions, personal interviews, focus groups and other methodologies that allow respondents to interact with the researcher are much more suitable for this purpose than close-ended questions, where the only possibility for interaction with the researcher is a tick in the box".

\section{Underlying value-judgements}

The second source of ambiguity flows from the non-factual nature of ethics. The decision as to whether something is good or bad, ethical or unethical, right or wrong depends on people's value-judgements. Inherent in discussions (and even in research) on whistle-blowing is the assumption that the whistle-blower is the moral hero and the organisation the villain. This often leads to debates about whether the whistle-blower's motives should play a role in defining a disclosure as whistle-blowing. Nicholas Lampert (1985, pp. 111-116) identifies four possible motives for blowing the whistle. In the first place, individuals might blow the whistle as a result of high moral standards that leave them no other choice. Fred Alford (2001, p. 43) calls this the "choiceless choice" of whistle-blowers. In the second place, whistle-blowers might want to distance themselves from the immoral activity as the risk of exposure is becoming too great. In the third place, the whistle-blower might want to expose the inequitable distribution of rewards, while, lastly, the whistle-blower might be acting out of vengeance. Latimer (2002: p. 24) adds the aspiration to become a hero as an additional motive.

Uys and Senekal (2008: pp. 38-40) analyse the motives of the whistle-blower in terms of a moral dilemma of having to choose between conforming to the morality of principle versus the morality of loyalty:

"Whistleblowers have to deal with the conflicting expectations of being loyal to the organisation and putting its interests first, while at the same time complying with the expectation that they should act in the best interest of the public" (Uys and Senekal, 2008: 40).

The problem with including the purity of the motive in the definition of whistle-blowing is that it is not that easy to determine unambiguously what people's motives are for any kind of behaviour. As Lampert (1985, p. 112) puts it: "Personal difficulties can be closely linked to, or can develop into, a wider social concern." People can also have mixed motives. If there is an element of personal grievance in the act of whistle-blowing, it does not necessarily mean that the disclosure could not simultaneously be in the public interest (Jackson, 1992, p. 265).

The perceived motives of the whistle-blower play a role in establishing the moral justifiability of whistle-blowing. The ethics of whistle-blowing could be analysed in terms of two moral purposes, i.e. whether the whistle-blowing is aimed at correcting a wrong or whether it is done in terms of a principle or duty. The first is called a consequentialist (Wilmot, 2000, pp. 1053-1054) or a utilitarian view (Rossouw, 2002, pp. 54-56). The second is known as a deontological view (Rossouw, 2002, pp. 49-54). The utilitarian evaluation of the justifiability of an unauthorised disclosure requires that the disclosure "does more good than harm; serves some purpose in correcting or preventing the wrongdoing concerned; is made in a responsible manner; and follows upon the exhaustion of internal channels of complaint and redress" (Hunt, 1998, p. 531). 
There are numerous problems with regard to this approach to determining the morality of whistle-blowing. It is extremely difficult for a prospective whistle-blower to assess the possible consequences of making a disclosure in advance. The list of requirements for making a responsible disclosure spelt out by Hunt (1998, p. 532) presupposes that making an unauthorised disclosure is a conscious, reasoned decision. As Rothschild and Miethe's (1999, p. 119) research exemplifies, most whistle-blowers assume this role almost by accident. They do not think that they are doing anything controversial. If anything, they think that they are doing their job and that their employer would be appreciative of their efforts. With regard to whistle-blowing, the deontological view (that argues that whistle-blowing results from adherence to some moral principle or duty) seems to make more sense, although it does not resolve any issues with regard to the choice between conflicting duties or principles, such as loyalty to the public or loyalty to your organisation.

This introduces the issue of the substance of the whistleblower's claim. A researcher cannot assume that all disclosures of supposed wrongdoing are necessarily accurate. The whistle-blower could possibly be mistaken or possess incomplete information. Or the whistleblower could be acting out of self-protection or malice (Perry, 1993, p. 81). The problem is that researchers are generally not in a position to do a complete investigation with regard to the accuracy of whistle-blowers' stories. Where whistle-blowers' stories have been reported in the media, or they had to face a disciplinary hearing or a court case, it may be possible to verify the basic facts. However, whistle-blowing is essentially as Alford (2001, p. 31) puts it: "about the quirky individual speaking out in a situation of moral ambiguity". When doing research on the ethics of whistle-blowing, the author tends to agree with Alford (2001, p. 32) when he argues the following:

"My question is not, 'Was the whistleblower right (pure, just, well-balanced)?' but 'What can the whistleblower's experience teach us about the fate of the individual in the organization?' To know this (that is, to be sure that there are not too many disturbances in the field), it is enough that the whistleblower not be crazy and that his or her case not be totally implausible. To demand that genuine whistleblowers be among the most rational, ethical, wellbalanced, and humane of humans would obscure most of what is important by making it impossible to ask the right question. Not 'Who is the whistleblower and is his case sounder than sound?' but 'What can we learn from the experience of the scapegoat?' is the question I am interested in".

In order to address the challenge of ambiguity, it is important that business ethics researchers should conceptualise their concepts clearly. If a full grasp of what the concept that is being researched entails is attained, the researcher would also be able to choose the most appropriate method to gain information about the phenomenon. The ambiguity that flows from the valuejudgements underlying certain business ethics concepts should be made explicit, and methods should be used that enable respondents to voice their understanding of the complexity of these concepts. In such a situation, personal interviews, life histories, focus groups and open-ended questions will be of value.

\section{CHOICE OF RESEARCH METHOD: EMBEDDEDNESS OF BUSINESS ETHICS IN THE ECONOMIC SETTING}

When appraising the comparative value of quantitative and qualitative research methods for a particular project, the embeddedness of business ethics in the economic setting needs to be kept in mind. This entails that the capacity of particular methodologies to uncover the choices of individual actors with regard to ethical behaviour as well as the impact of the economic setting on ethical behaviour need to be assessed.

Rossouw (2001, p. 204) is of the opinion that quantitative methods such as social surveys, although useful in accessing the attitudes of individuals, would be less valuable in determining actual ethical behaviour. This debate between the value of quantitative versus qualitative research is ongoing. Unfortunately, the subject matter of the social sciences is such that most of our data on attitudes as well as behaviour stem from self-reports by our respondents. And, self-reports are necessarily vulnerable to various influences with regard to a self-presentation or social desirability bias. This implies that responses "may be subject to socially desirable response problems of honesty of recall, accuracy, willingness to report socially disapproved behavior, and other sources of bias" (Akande, 2001, p. 250).

The assessment of whether a qualitative or quantitative study provides us with more truthful answers relates to the question as to which environment would be more conducive to socially desirable answers. Zeller (1993, p. 103) defines social desirability as "a situation in which respondents say what they think the researcher wants to hear rather than what they believe (or what they have done)". Social desirability is linked to the possibility of a self-presentation bias where respondents could massage their stories or adapt their replies in terms of "their perception of the social desirability of those answers. An answer that is perceived to be socially desirable is more likely to be endorsed than one that is not" (Bryman, 2001, p. 123).

In their study on the public service ethic of whistle-blowers, Brewer and Selden (1998: p. 427-428) employed a number of techniques in order to diminish the possible bias introduced 
by self-reporting. They used a large survey that did not focus on whistle-blowing exclusively but phrased questions in general, hypothetical terms that would not trigger attempts at justification. These questions were alternated by questions that required reports on concrete events, which generally tend to be more accurate and objective. Anonymity was also ensured, which reduces the danger of social desirability responses.

The occurrence of social desirability responses does not mean that respondents are consciously lying. Various issues are at stake. Alford (2001, p. 8) expresses it very well when he talks about the inability of whistle-blowers to remain loyal to their story.

"For the whistleblower to be loyal to his or her story, he or she would have to know and accept some terrible truths about the world, above all that his sacrifice will not be redeemed. No one will be saved by his suffering, not even himself. The organization he worked for will not be made better, and those who worked with him will not have become more moral by virtue of his example".

Comparisons of qualitative and quantitative studies demonstrated a greater vulnerability to self-presentation bias among qualitative studies. This is attributed to the influence of the amount of privacy the respondents are afforded when answering the researcher's questions and the degree of anonymity they can reasonably expect to receive, both of which are largely absent in the case of interviews and, especially, focus groups. Self-presentation bias is also influenced by the extent to which respondents are convinced of the seriousness of the scientific endeavour and the importance of their contribution to it (Catania et al., 1993, p.151; Uys, 2002).

Rossouw (2004, p. 29) argues for the use of methods that would enable the researcher to uncover both the moral attitudes and intentions of individuals, for example by means of self-report surveys, as well as their actual moral behaviour, which would require more phenomenological strategies in a naturalistic setting. Documentary studies can also assist in accessing the institutionalisation of moral behaviour in the organisational context. A variety of research methodologies is therefore required to capture the full complexity of cultural embeddedness in organisations.

\section{CHOICE OF RESEARCH METHOD: SENSITIVITY}

This brings us to the final methodological challenge that we need to consider, which is the sensitive nature of business ethics research. Research on whistle-blowing exemplifies enquiries into experiences of respondents that reflect their value as humans and the essence of their being. This is the case not only with the whistle-blowers but also with the organisations that they belonged to who are insistent on protecting their reputations.

A technique that is particularly appropriate for conducting sensitive research is the narrative interview as it "envisages a setting which encourages and stimulates interviewees to tell a story about some significant event in the informants' life" (Bauer, 1996: 2). This technique entails that the interviewer presents the initial central topic to the respondent. The respondent is invited to tell his or her story. The narration is then followed by a questioning phase, during which clarifications of the story are sought in a non-threatening manner.

While sensitive research can possibly result in the appearance of a social desirability bias, this kind of research also tends to be vulnerable to non-response. Interviewing whistle-blowers does not however seem to present a serious obstacle. Most whistle-blowers seem to have a deeply felt need to communicate their story to the world as part of the process of dealing with their experiences. Non-response could be more of an issue when trying to get access to employers to get their side of the story. On the other hand, a self-administered survey would probably be less susceptible to non-response, as the respondents are able to remain anonymous.

\section{IN CONCLUSION: A WAY FORWARD}

When conducting research in the field of the sociology of business ethics, researchers should consider issues of theoretical coherence, ambiguity, embeddedness and sensitivity when making decisions on the research design and methodology to be employed. It is particularly important to evaluate the advantages and disadvantages of combining qualitative and quantitative research designs.

In developing a strategy for combining quantitative and qualitative measures, Zeller (1993) provides a description of the essential characteristics of the quantitative sample survey and qualitative focus groups. He argues that the shortcomings of the one approach tend to be the strengths of the other. "[C]ombining these approaches into a single coherent research strategy" (Zeller, 1993, p. 96) enables the researcher to offset the disadvantages of the one by the inclusion of the advantages of the other. Similarly, Quirk and Rhodes (1998, p. 2) emphasise the "significance of survey methodology in influencing how findings are produced and the importance of qualitative research in complementing and questioning quantitative measures". They identify two ways in which qualitative research into behaviour complements quantitative research. First, while quantitative measures enable us to assess which factors play a role in the extent to which certain types of behaviour occur, qualitative measures facilitate our understanding of the ways in which and the reasons why such behaviour 
occurs. Second, qualitative measures enhance our insight into the perceptions of participants regarding their behaviour.

Research in the sociology of business ethics should therefore consciously ascertain the value of using an integrated multistrategy approach by combining qualitative and quantitative measures. Such an approach would enable whistle-blowing researchers to develop an understanding of the experiences of whistle-blowers by means of a qualitative design such as narrative interviews, while a self-administered questionnaire distributed in an organisational setting could provide access to the extent to which employees would be prepared to disclose information about perceived wrongdoing. A combination of qualitative and quantitative designs would facilitate a study of the motivations, and the cognitive, affective and ethical decision making processes of individual actors as well as an investigation of these processes in the larger social context, particularly as it relates to the organisation.

\section{ENDNOTE}

1. Examples of other concepts in business ethics where conceptualization is debated are corruption (Widmalm, 2008, pp. 114-118), denial (Cohen, 2001, pp. 3-20) or loyalty (Coughlan, 2005).

\section{REFERENCES}

Abend, G. 2008. 'Two main problems in the sociology of morality'. Theory and Society. 37: 87-125.

Akande, A. (2001). 'Risky Business: South African Youths and HIV/AIDS Prevention', Educational Studies, 27(3):237-256.

Alford, C.F. 2001. Whistleblowers: Broken Lives and Organizational Power. London: Cornell University Press.

Bauer, M. 1996. 'The Narrative Interview: Comments on a Technique for Qualitative Data Collection'; at: 64.233.167.104/search?q=cache: M26b7ilgNgwJ. Available from: www.Ise.ac.uk/collections/methodology Accessed on 23 February 2007.

Ben-Yehuda, N. 2001. Betrayals and Treason: Violations of Trust and Loyalty. Cambridge, MA: Westview.

Bok, S. 1980. 'Whistleblowing and Professional Responsibilities.' Ethics Teaching in Higher Education 11:277-295.

Brewer, G.A. and Selden, S.C. 1998. 'Whistle blowers in the Federal civil service: New evidence of the public service ethic'. Journal of Public Administration Research and Theory 8(3): 413-39.

Bryman, A. 2001. Social Research Methods. Oxford: Oxford University Press;

Calland, R. and Dehn, G. 2004. Whistleblowing around the World: Law, Culture and Practice. Cape Town: The Open Democracy Advice Centre and London: Public Concern at Work.

Catania, J.A., Turner, H., Pierce, R.C., Golden, E., Stocking, C., Binson, D. and Mast, K. (1993). Response bias in surveys of AIDS-related sexual behaviour, in Ostrow, D.G. and Kessler, R.C. (eds.). Methodological issues in AIDS behavioural research. New York: Plenum Press.

Cohen, S. 2001. States of denial: Knowing about Atrocities and Suffering. Cambridge: Polity.

Coughlan, R. 2005. 'Employee Loyalty as Adherence to Shared Moral Values', Journal of Managerial Issues, 17 (1): 43-57.

Davis, M. 2004. 'Some Paradoxes of Whistleblowing,' In Beauchamp, T.L. and Bowie, N. (eds.). Ethical Theory and Business, seventh edition. New
Jersey: Prentice Hall.

Frederickson, H.G. 1993. Ethics and Public Administration, (M.E. Sharpe, London).

Hendry, J. 2001 'After Durkheim: An Agenda for the Sociology of Business Ethics'. Journal of

Business Ethics, 34(3/4): 209-218.

Hoffman, W.M. and Moore, J.M. 1982. 'What is Business Ethics?' A Reply to Peter Drucker', Journal of Business Ethics 1: 293-300.

Hunt, G. 1998. 'Whistle-Blowing.' Encyclopedia of Applied Ethics 4: 525535.

Glazer, M.P. and Glazer, P.M. 1989. The Whistleblowers: Exposing Corruption in Government and industry. New York: Basic Books.

Hendry, J. 2001. 'After Durkheim: An agenda for the sociology of business ethics'. Journal of Business Ethics 34 (3/4): 209-217.

Jackson, J. 1992. 'Coming to Ethical Terms. Motive and Morality'. Business Ethics. A European Review 1(4):264-266.

Johnson, R.A. 2003. Whistleblowing: When it Works- and Why. London: Lynne Riener Publishers.

Jubb, P.B. 1999. 'Whistleblowing: A Restrictive Definition and Interpretation', Journal of Business Ethics 21: 77-94.

Kloppers, P. 1997. 'Behoort die whistle blower beskerm te word?' Stellenbosch Law Review, 8(2): 237-248.

Lampert, N. 1985. Whistleblowing in the Soviet Union: Complaints and Abuses under State Socialism London: Macmillan.

Latimer, P. 2002. 'Reporting suspicions of money laundering and 'whistleblowing': The legal and other implications for intermediaries and their advisers'. Journal of Financial Crime, 10 (1): 23-29.

Miceli, M.P. and Near, J.P. 2008. Whistleblowing in Organizations. New York: Routledge

Miceli, M.P. and Near, J.P. 1992. Blowing the Whistle: The Organizational and Legal Implications for Companies and Employees. New York: Lexington Books.

Miethe, T.D. 1999. Whistleblowing at Work: Tough Choices in Exposing Fraud, Waste, and Abuse on the Job. Boulder, Colorado: Westview Press.

Park, H. and J. Blenkinsopp 2009, 'Whistleblowing as planned behavior - A survey of South Korean police officers', Journal of Business Ethics, 85: 545-556.

Perry, J.L. 1993. 'Whistleblowing, Organizational Performance, and Organizational Control', in H.G. Frederickson, (ed), Ethics and Public Administration, London: M.E. Sharpe, London. pp 79-99.

Petersen, J.C. and Farrell, D. 1986. Whistleblowing: Ethical and Legal Issues in Expressing Dissent. Dubuque, lowa: Kendall/Hunt.

Quirk, A. and Rhodes, T. 1998. 'Unsafe protected sex': Qualitative insights on measures of sexual risk. AIDS Care, 10(1): 105-114.

Rossouw, D. 2004. Developing Business Ethics as an Academic Field. Ben Africa; Johannesburg.

Rossouw, G.J. 2001. 'Research in business ethics.' Koers, 66(3): 197-211. Rossouw, G.J. 2002. Business Ethics in Africa. Oxford: Oxford University Press.

Rothschild, J. and Miethe, T. D. 1994. 'Whistle-Blowing as Resistance in Modern Work Organizations', in J.M. Jermier, D. Knights and W.R. Nord (eds) Resistance and Power in Organizations, London: Routledge. pp. 252-73.

Rothschild, J. and Miethe, T. D. 1999 'Whistle-Blower Disclosures and Management Retaliation', Work and Occupations 26(1): 107-28.

Singer, M., Mitchell, S., and Turner, J. 1998. 'Consideration of Moral Intensity in Ethicality Judgements: Its Relationship with Whistleblowing and Need-for-cognition', Journal of Business Ethics 17: 527-541.

Somers, M.J. and Casal, J.C. 1994. 'Organizational Commitment and Whistleblowing', Group and Organization Management 19(3): 270-284.

Starck, K. 2001. 'What's Right/Wrong with Journalism Ethics Research?'. Journalism Studies 2(1): 133-152.

Trevino, L.K. and Weaver G.R. 1994. 'Business ethics/business ethics: One field or two?' Business Ethics Quarterly 4(2): 113-125.

Uys, T. 2002. 'Students, sex and Aids: A methodological controversy'. Society in Transition, 33(3): 382-402. 
Uys, T. 2008. "Rational loyalty and whistleblowing: The South African context." Current Sociology, 56(6): 907-924.

Uys, T. and Senekal, A. 2008. Morality of principle versus morality of loyalty: The case of whistleblowing. African Journal of Business Ethics 3(1): 38-44.

Vinten, G. 1994. Whistleblowing: Subversion or Corporate Citizenship? London: Paul Chapman.

Vanderkerchhove, W. 2006. Whistleblowing and Organizational Social Responsibility: A Global Assessment. England: Ashgate Publishing.

Westin, A.F. 1981. Whistleblowing! Loyalty and Dissent in the Corporation. New York: McGraw-Hill.

Widmalm, S. 2008. Decentralisation, Corruption and Social Capital: From
India to the West. Sage: New Delhi.

Wilmot, S. 2000. 'Nurses and Whistleblowing: The Ethical Issues', Journal of Advanced Nursing 32(5): 1051-1057.

Zeller, R.A. 1993. 'Combining Qualitative and Quantitative Techniques to Develop Culturally Sensitive Measures', In D.G. Ostrow. and R.C. Kessler (eds.), Methodological Issues in AIDS Behavioural Research, New York: Plenum Press.

How to cite this article: Details updated once issue gets online ${ }^{* * *}$.

Source of Support: Nil, Conflict of Interest: None declared

\section{AUTHOR}

Tina Uys is currently Professor of Sociology, Chairperson of the department and Director of the Centre for Sociological Research at the University of Johannesburg.

\section{Staying in touch with the journal}

1) Table of Contents (TOC) email alert Receive an email alert containing the TOC when a new complete issue of the journal is made available online. To register for TOC alerts go to www.ajobe.org/signup.asp.

\section{2) RSS feeds}

Really Simple Syndication (RSS) helps you to get alerts on new publication right on your desktop without going to the journal's website. You need a software (e.g. RSSReader, Feed Demon, FeedReader, My Yahoo!, NewsGator and NewzCrawler) to get advantage of this tool. RSS feeds can also be read through FireFox or Microsoft Outlook 2007. Once any of these small (and mostly free) software is installed, add www.ajobe.org/rssfeed.asp as one of the feeds. 
Reproduced with permission of the copyright owner. Further reproduction prohibited without permission. 